\section{Auroral Phenomena}

IT is perhaps worth a note that my daughter saw at Folkestone a very unusual phenomenon on the evening of January 25 , a little before 6.30 . Some distance to the left of Orion (for the night was clear and starry) she observed a small cioud of a bright golden hue, from which streamers of great brilliancy darted in various directions, the cloud alternately paling and brightening. She describes the streamers as like small meteors, leaving trails of light behind them.

Athenzum Club, February I2

\section{Ozone}

IN reply to Mr. Capron (NAtuRE, vol. xxiii. p. 219) the following explanation may perhaps serve :-

On a flat piece of brass two strips of paper are laid, one plain white, the other prepared. With a clean camel-hair brush they are moistened liberally with pure alcohol. This is then burnt off, firing it with a spirit flame; the plain paper remains clear and white, the prepared paper (beginning at the edges) gradually changes to a purple brown. On immersing both strips in clean water the plain paper still remains white, prepared paper changes to a deep purple (No. 8, Negretti's scale).

In about an hour this deep purple colour fades away precisely in the same zuay as if the slip had been ozonized by exposure for a day or two to the air. It may be added that if the prepared slip is not plunged into water the purple brown tint remains for several days.

The experiment suggested by $\mathrm{Mr}$. Capron has been made, using a very delicate gold-leaf electrometer. When this is uncharged there is no apparent effect; when charged either directly or inductively with either positive or negative electricity the gold leaves collapse, the charge appearing to be dissipated with the flame.

I may add, when the leaves are charged the alcohol is lighted on the plate of the electrometer with a glass rod dipped in alco. hol, care being taken to prevent the discharge by conduction. The above experiments have been performed in an ordinary study, but $I$ cannot say they are very conclusive.

Mr. Capron states "ozone is very strong just now," and he obtains No. 10 (Negretti's scale) at an inland town. This is a very high number. I have repeatedly obtained this number at Hunstanton on the Wash (Norfolk), where I made experiments daily for a month. The ozone cage was kept in the shade, a fine cloudless day with cold north east wind blowing, and one day's exposure. I have been engaged for some years in testing for ozone on the coast to see if its abundance, or deficiency, is in any way dependent on the physical and geological conditions of the shore. My experiments are not sufficiently advanced to be published, but the three following conditions have always been found to be present where ozone is abundant.

1. A long sandy shore exposed for some hours to the sun's rays.

2. Cloudless sky, with cold north or east wind.

3. An abundance of phosphorescent light from the presence of Noctiluca miliaris with the evening flow of tide.

This town is singularly deficient in ozone. After numercus experiments I have as yet only obtained No. I (Negretti's scale). Whether this deficiency may not have some connection with our notoriously great infantile mortality of the autumn is a question for further consideration.

Leicester, January 27

J. P.

\section{Citania}

I HAVE not had an opportunity of reading NATURE for some time, but $I$ am told that in a late number there is : ome mention of a so-called "Pompeii" near Braga in Portugal.

I do not presume to write as a learned antiquarian; but having lived for some years within thirty miles of Citania, and having often visited the place and examined the ruins with a wish to gain some explanation of their mystery, I venture to write as an ordinary witness.

In no sense can Citania he described as a Celtic Pumpeii ; it is merely a collection of circular buildings erected so close to each other as almost to touch, and grouped on the top of a hill which runs out as a spur from the higher ground behind it, and overlooks the rich valley teneath it. The walls have fallen, and the stones which composed them remain in situ, generally visible, though more or less overgrown with grass. From the founda- tions it seems that these round houses must have been some ten feet in diameter internally, with walls eighteen inches thick. The original height of the walls may be inferred, from the quantity of stones fallen, to have been some twelve or fifteen feet.

My ntmost examination discovered scarcely anything beyond some shattered bits of coarse pottery. But over the surface of the hill there are still lying about many well-shaped round stones about twenty inches in diameter, which I always thought to be band millstones. These seemed to me to afford the most likely solution of any mystery connected with the place, and I inferred it was a place of security, to which the corn of the district round was carried. The apparent absence of water forbade the supposition that it was a place of permanent abcde. I never could see any necessity for referring its origin to Celtic time. The buildings were probably used, and possibly only date from much later days. Remembering the condition of that district as being the debatable ground lying between the Asturian kingdom in the north and the moors in the south, and open to sudden and transient incursions from either side, the utility of such a place to the farmers of that district seems evident. A Portuguese gen tleman, whose name I forget, has so far interested himself in the place as to rebuild one of the circular buildings in what he conceives its original condition, and inside he has collected any remains of antiquarian interest that he could 'scrape together. Unforiunately his enthusiasm for forming a kind of local museum has led him to carry to it what never belonged to the place. For outside his museum there is a large granite slab, which in character is utterly foreign to the place, and long mystified me. This "Pedra Formosa," as it is called by the neighbouring villagers, is about nine or ten feet long, six feet high, with an average thickness of one foot, and nust weigh six or seven tons. It looks like a pretentious façade stone, which has survived the building to which it was once attached. It has some carving about it, and signs which may or may not have any meaning in them. But whatever the stone was, it has no right to be where it is ; for one day, in a conversation with a local farmer at the inn in the valley, I learnt the fact that some years ago all the farmers of the neighbourhood combined, and yoking thirty-nine pair of bullocks together, dragged the said stone from the valley below, where from time inmemorial it had been lying, and added it in triumph to the other objects of the museum.

I may add that during my stay in Portugal I corresponded with the late Senhor Herculano, the Portuguese historian, on the subject, and I believe I have stated his conclusions.

Sutton Montis Rectory, Castle Cary, February 8

\section{The Recent Severe Weather}

YouR corresfondent H. W. C. in his communication on the ahove in NATURE, vol. xxiii, p. 329, qiotes Mr. Lowe's theory of an eleven-year cycle of "great frosts," and after giving the dates upon which that theory is apparently based, says: "There are some variations in the lengths of the intervening periods, but there is a distinct recurrence of eleven-year epochs."

With the first part of this sentence I quite agree, but I fail to see the very least ground for the latter part of it, the intervals taken in order being as follow's : $-9,3,6,18,3,16,4$, and ro years. Three intervals approximating to eleven years can be "screwed" in by manipulating the years between which you reckon, disregarding inconvenient ones and using others which suit better ; but surely this cannot be held sufficient to justify the statement, such a method of dealing with the figures being, it is scarcely necessary to point out, quite unallowable.

I have noticed before that when the discovery of similar epochs for abnormal heat, cold, rain, \&c., have been announced, a similar method of dealing with dates has been fcllowed to that which seems to have been adopted in this case. F. M. S.

February 3

THE epochs which show recurrence are obtained by "manipulating" the figures in the following manner:-

December 1801 to January 1814 , interval i2 years 2 months.

$\begin{array}{llllrlll}, " & 1810 & \text { " } & \text { I820, } & 9 & , & 2 & ,\end{array}$

(It should here be remarked that a long but not "great" frost was experienced in the winter of $1849-50$; as it was not severe enough to entitle it to the designation of great frost it was 